\title{
ON GENERALIZED GEOMETRIC DIFFERENCE OF SIX DIMENSIONAL ROUGH IDEAL CONVERGENT OF TRIPLE SEQUENCE DEFINED BY MUSIELAK-ORLICZ FUNCTION
}

\author{
A. ESI AND N. SUbRAMANIAN
}

Abstract. We introduce a rough ideal convergent of triple sequence spaces defined by MusielakOrlicz function, using an six dimensional infinite matrix, and a generalized geometric difference Zweier six dimensional matrix operator $B_{(a b c)}^{p}$ of order $p$. We obtain some topological and algebraic properties of these spaces.

Mathematics subject classification (2010): 40F05, 40J05,40G05.

Keywords and phrases: Triple sequences, Wijsman rough convergence, strongly admissible ideal, cluster points, six dimensional matrix, geometric difference.

\section{REFERENCES}

[1] M. Aiyub, A. Esi And N. Subramanian, The triple entire difference ideal of fuzzy real numbers over fuzzy $p$-metric spaces defined by Musielak Orlicz function, Journal of Intelligent \& Fuzzy Systems, 33 (2017), 1505-1512.

[2] S. Aytar, Rough statistical convergence, Numer. Funct. Anal. Optim., 29 (2008), No. 3, $291-303$.

[3] A. ESI AND E. SAVAS, On lacunary statistically convergent triple sequences in probabilistic normed space, Appl. Math. Inf. Sci., 9 (2015), No. 5, 2529-2534.

[4] S. Debnath, B. SARMA And B. C. DAS,Some generalized triple sequence spaces of real numbers, J. Nonlinear Anal. Optim., 6 (2015), No. 1, 71-79.

[5] A. J. DutTA, A. Esi AND B. C. TRIPAThy, Statistically convergent triple sequence spaces defined by Orlicz function, J. Math. Anal., 4, (2013), No. 2, 16-22.

[6] Y. FADILE KARABABA AND A. EsI, On some strong zweier convergent sequence spaces, Acta Univ. Apulensis Math. Inform., 29 (2012), 9-15.

[7] P. K. Kamthan And M. Gupta, Sequence Spaces and Series, Lecture notes, Pure and Applied Mathematics, Marcel Dekker Inc., New York, 1981.

[8] V. A. Khan, K. Ebadullah, A. Esi, N. Khan and M. ShafiQ, On paranorm Zweier Iconvergent sequence spaces, J. Math., 2013, Article ID 653501, 6pp.

[9] J. Lindenstrauss And L. TZAFriRi, On Orlicz sequence spaces, Israel J. Math., 10 (1971), 379390.

[10] J. Musiela K, Orlicz Spaces, Lectures Notes in Mathematics 1034, Springer-Verlag, 1983.

[11] S. K. Pal, D. Chandra And S. DutTa, Rough ideal Convergence, Hacet. J. Math. Stat., 42 (2013), No. 6, 633-640.

[12] H. X. PHU, Rough convergence in normed linear spaces, Numer. Funct. Anal. Optim., 22 (2001), 201-224.

[13] A. Sahiner, M. Gurdal and F. K. Duden, Triple sequences and their statistical convergence, Selcuk J. Appl. Math.,8 (2007), No. 2, 49-55.

[14] A. SAhiner And B. C. Tripathy, Some I related properties of triple sequences, Selcuk J. Appl. Math., 9 (2008), No. 2, 9-18.

[15] N. Subramanian AND A. Esi, The generalized tripled difference of $\chi^{3}$ sequence spaces, Global Journal of Mathematical Analysis, 3 (2015), No. 2, 54-60. 